\title{
Tibia pilon kırıklarının cerrahi tedavi sonuçları
}

\author{
The results of surgical treatment for tibial pilon fractures \\ Serdar Üner, Hayati Öztürk, Seyran Kılınç*, Okay Bulut, Gündüz Tezeren, \\ Zekeriya Öztemur
}

Ortopedi ve Travmatoloji Kliniği (Uzm. Dr. S. Üner), Kilis Devlet Hastanesi, TR-79000 Kilis, Ortopedi ve Travmatoloji Anabilim Dalı (Doç. Dr. H. Öztürk, Prof. Dr. O. Bulut, Prof. Dr. G. Tezeren, Yrd. Doç. Dr. Z. Öztemür), Cumhuriyet Üniversitesi Tıp Fakültesi, TR-58140 Sivas, Ortopedi ve Travmatoloji Kliniği (Uzm. Dr. S. Kılınç), Harput Devlet Hastanesi, TR-23200 Elazı̆̆

\begin{abstract}
Özet
Amaç. Bu çalışmada amacımız, cerrahi ile tedavi edilen tibia pilon kırıklarının orta dönem klinik ve radyolojik sonuçlarını incelemektir. Yöntem. Cumhuriyet Üniversitesi Tıp Fakültesi Ortopedi ve Travmatoloji Kliniği'nde Eylül 2004-Eylül 2011 yılları arasında cerrahi olarak tedavi edilmiş 43 Pilon kırıklı hastadan, son kontrolleri yapılan 25 hastanın 26 Pilon kırığı bu çalışmaya dahil edildi. Bulgular. Olguların 7'si kadın, 18'si erkekti. Olgularımızın yaş ortalaması 47,4 (Aralık 20-74). Olguların 8' i açık kırıktı (2'si tip 1, 2'si tip 2, 4'ü tip 3). Ruedi-Allgöwer sınıflamasına göre 13 hastada tip 1, 8 hasta tip 2 ve 5 hastada tip 3 kırık saptandı. Etiyolojide yüksekten düşme ilk sırayı almaktadır. On dokuz olguda aynı zamanda fibula kırı̆̆ı vardı. Yirmi altı Pilon kırığının; 17'sine tek seanslı cerrahi girişim uygulandı. Yirmi altı Pilon kırığının 9'una birden fazla sayıda cerrahi girişim ( 7 olguya; 2 cerrahi girişim, 2 olguya; 3 cerrahi girişim) uyguland. İki olguda kompartman sendromu tanısı ile fasiotomi açıldı. İki olguda cilt nekrozu gelişmesi nedeniyle yüzeyel cilt greftlemesi uygulandı. Üç olguda yara yeri enfeksiyonu gelişmesi nedeniyle implant çıkarımı uygulandı. Beş olguya allogreft (Deminarelize Bone Matrix ve cancellos chips) uygulandı. Sekiz olguda Sudeck artrofisi gelişti, 7 olguda osteoartrit gözlendi. Değerlendirmeler de AOFAS kriterleri kullanıldı. Yirmi altı Pilon kırığının 15'inde AOFAS skoru 70 ve üzeri çıktı. On olguda AOFAS skoru 50-70 arası çıktı. İki olguda AOFAS skoru 30-50 arası çıktı. Sonuç. Pilon kırıkların da başarılı sonuç alabilmek için çok iyi preoperatif planlama yapılmalıdır. Pilon kırıklarının tümü için geçerli tek bir başarılı tedavi yöntemi yoktur. Her kırığın ayrı olarak değerlendirilmesi, tedavinin iyi planlanarak cerrahi ilkelere uyulması gereklidir.
\end{abstract}

Anahtar sözcükler: Tibia, pilon kırığı, içten tesbit, artroz

\begin{abstract}
Aim. In this study our aim was to evaluate medium term results of tibial pilon fractures clinically and radiologicaly that treated with surgical. Method. From September 2004 to September 2011, 43 patients were surgically treated for pilon fracture, after the final checks of 25 patiensts 26 pilon fracture evaluated for this study in Cumhuriyet University, Department of Orthopedics and Traumatology. Results. Seven of the cases were women and 18 men. Mean age was 47.4 years (20-74). Eight of the cases were open ( 2 type I, 2 type II and 4 type III). There were 13 type 1,8 type 2 , and 5 type 3 fractures according to Ruedi-Allgöwer respectively. Falling from the height take the first place in etiology. At the same time 19 fibula fracture observed. 26 out of 17 pilon fracture patients were treated by one-stage operations. 26 out of 9 Pilon fracture were treated by multiple operations (for 7 cases; 2 operation, for; 2 cases 3 operations). In 2 cases fasciotomy was operated with compartment diagnosis. In 2 cases due to developing skin necrosis superficial skin grafting were treated. In 3 cases due to the development of wound infection removal implant were treated. In 5 cases allogreft (Deminarelized Bone Matrix \& cancellos chips) were treated. In 8 cases Sudeck atrophy developed, In 7 cases osteoarthritis observed. AOFAS criterias were used in evaluation. The score of AOFAS was found 70 in 15 of 26 pilon fractures. In 10 cases the score of AOFAS was found between 50-70. In 2 cases the score of AOFAS was found between 30-50. Conclusion. Pilon fractures of the preoperative planning should be done very well to get a successful outcome. A single successful treatment for pilon fractures do not apply to all. In a separate evaluation of each fracture, surgical treatment is well planned and principles must be followed.
\end{abstract}

Keywords: Tibia, pilon fracture, internal fixation, arthrosis 
Geliş tarihi/Received: 24 Temmuz 2013; Kabul tarihi/Accepted: 08 Ekim 2013

\section{*İletişim adresi:}

Dr. Seyran Kılınç, Ortopedi ve Travmatoloji Kliniği, Harput Devlet Hastanesi, TR-23200 Elazı̆̆. E-posta: seyrankilinc@ hotmail.com

\section{Giriş}

Pilon kırıkları, tibianın distal eklem yüzünü ve metafizini ilgilendiren, genelde yüksek enerjili travma sonrası majör yumuşak doku yaralanmasının eşlik ettiği kompleks kırıklardır. Pilon kırıkları alt ekstremite kırıklarının \%1'ini, tüm tibia kırıklarının da yaklaş1k \%5-10'unu oluştururlar [1].

Yaralanmanın ileri boyutlarda olması, kıkırdak eklem yüzünün hasarlanması ve yumuşak doku ödemi sebebiyle ortopedik cerrahlar için her zaman sorunlu kırıklar olarak kabul edilmiştir [2].

Tedavide amaç eklem yüzünün devamlılığını ve uyumunu sağlamak, erken harekete izin verecek şekilde kemiği stabil hale getirmek ve yumuşak dokuyu korumaktır. Eklemin stabil tespiti sonucu erken hareketle fonksiyonel olarak iyileşme görüşü pratikte her zaman kolay uygulanamamaktadır. Kemiğin ve tibia distalindeki yumuşak dokunun kanlanmasının bozulması, kırı̆̆ın eklem dışı parçalı uzantısı ve kemik kitlesinin kaybı sonucunda pilon kırıklarının stabil tespiti zor ve bazen de imkansız hale gelmekte, bu da ortopedik cerrahları zor durumda birakmaktadır [3, 4].

$\mathrm{Bu}$ çalışmada amacımız; kliniğimizde cerrahi olarak tedavi edilip rehabilitasyon uygulanan olguların klinik ve radyolojik sonuçlarını değerlendirmekti.

\section{Gereç ve yöntem}

Cumhuriyet Üniversitesi Tıp Fakültesi Ortopedi ve Travmatoloji Kliniği’nde Eylül 2004Eylül 2011 yılları arasında cerrahi olarak tedavi edilmiş 43 Pilon kırıklı hastadan, son kontrolleri yapılan 25 hastanın 26 Pilon kırığ 1 bu çalışmaya dahil edildi. 18' i erkek 7'si kadın olan olgularımızın yaş ortalaması 47,4 (Aralık 20-74) idi. 12 hastada sağ, 12 hastada sol, 1 hastada bilateral Pilon kırı̆̆ı mevcuttu.

Gustillo-Andersen sinıflamasına göre 2 olguda tip I $(\% 7,6), 2$ olguda tip II $(\% 7,6), 4$ olguda tip III $(\% 15,3)$ olmak üzere 8 olguda $(\% 30,7)$ açık kırık tespit edildi [5]. Kırık nedeni 10 olguda (\%40) yüksekten düşme, 6 olguda (\%24) ayağın üzerine cisim düşmesi, 4 olguda merdivenden düşme (\%16), 3 olguda araç içi trafik kazası (\%12), 2 olguda araç dışı trafik kazası ( $\% 8)$ olarak belirlendi.

Çalışmamızda Ruedi-Allgöwer kırık sınıflaması kullanıldı [6]. On üç kırık RuediAllgöwer tip $1(\% 50), 8$ kırık tip $2(\% 30,7), 5$ kırık tip $3(\% 19,3)$ olarak sınıflandırıldı (Resim 1).

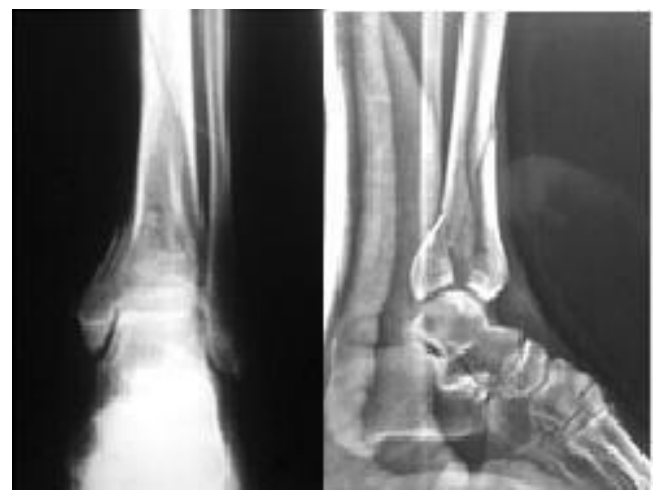

Resim 1. Reudi-Allgöwer Tip II kırıklı olgunun ameliyat öncesi AP ve lateral grafileri. 
Sekiz (\%32) olguda aynı zamanda başka organ ve kemik yaralanması mevcuttu. Lokal yumuşak doku hasarını değerlendirmek için Tscherne ve Goetzen tarafindan tarif edilen sinıflamayı kullandık. Dokuz olguda grade I $(\% 34,6), 7$ olguda grade II $(\% 26,9), 5$ olguda grade III $(\% 19,2)$ ve 5 olguda grade IV $(\% 19,2)$ yumuşak doku yaralanması mevcuttu.

Yaygın ödemin gerilemesi ve yumuşak doku hasarının iyileşmesi için cerrahi girişim ortalama 7,25 (Aralık 3-16) gün geciktirildi. Beş olguda bekleyemeyecek açık kırık olduğu için birinci gün acil şartlarda opere edildi (3 olguya uniplan eksternal fiksatör, 2 olguya interfragmanterik vida ve $\mathrm{K}$ teli).

Açık kırığı olan olgulara önce irrigasyon ve yara debridmanı yapıldı. Tetanoz ve gazlı gangren profilaksisi için tetanoz aşısı, serum anti gangren ve serum anti tetanoz uyguland1. Birinci kuşak sefalosporin (sefazolin sodyum) 3x1gr IV başlandı.

Yirmi altı Pilon kırığının; 17'sine (16 hasta ve bilateral Pilon kırığı olan hastanın sağ tarafi) tek seanslı cerrahi girişim uyguland1. Dört olguya eksternal fiksatör (3 uniplan, 1 ilizarov), 3 olguya hibrid eksternal fiksatör ( 3 uniplan)+açık redüksiyon internal tesbit (3 interfragmanterik vida ve $\mathrm{K}$ teli), 10 olguya açık redüksiyon internal tesbit(8 interfragmenterik vida, 2 DCP plak) uygulaması yapıldı. Yirmi altı Pilon kırığının 9'una ( 8 hasta ve bilateral Pilon kırıklı hastanın sol tarafi) birden fazla sayıda cerrahi girişim (7 olguya 2 cerrahi girişim, 2 olguya 3 cerrahi girişim) uygulandı. Dokuz Pilon kırığına yapılan ilk cerrahi girişim sırasında; 3 olguya eksternal fiksatör (3 uniplan), 2 olguya hibrid eksternal fiksatör ( 2 uniplan)+açık redüksiyon internal tesbit (2 interfragmanterik vida ve $\mathrm{K}$ teli), 4 olguya açık redüksiyon internal tesbit ( 2 interfragmanterik vida ve $\mathrm{K}$ teli, 2 distal anatomik plak) uygulandı. İkinci cerrahi girişim sırasında 7 olguya eksternal fiksatör ( 4 bilgisayar destekli eksternal fiksatör, 2 ilizarov, 1 uniplan), bir olguya hibrid eksternal fiksatör (uniplan)+ açık redüksiyon internal tesbit (interfragmanterik vida ve $\mathrm{K}$ teli), Bir olguya açık redüksiyon internal tesbit (distal anatomik plak)+allogreftleme uyguland1. Üçüncü cerrahi girişim 2 olguya uygulandı. Bir olguya osteotomi+ilizarov diğer olguyada artrodez uygulandı (Resim 2).

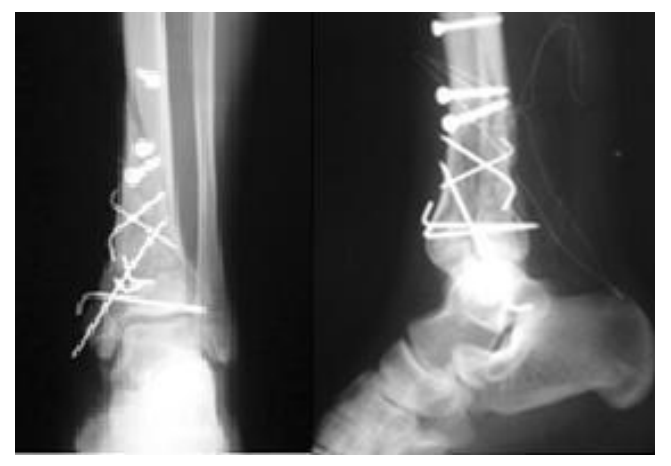

Resim 2. Erken ameliyat sonrası AP ve lateral grafisi.

On dokuz olguda $(\% 73,07)$ aynı zamanda fibula kırığı mevcut idi. On dokuz fibula kırı̆̆ının 18 'ine osteosentez uygulandı. Fibula tespiti için; $8(\% 42,1)$ olguya $3,5 \mathrm{~mm}$ DCP plak, $8(\% 42,1)$ olguya intramedüller K teli, $2(\% 10,5)$ olguya interfragmanter vida kullanıld1.

Operasyon sonrası ekstremite kısa bacak atel konularak eleve edildi. Ameliyat öncesi tek doz 1gr sefazolin sodyum ile başlanan profilaktik antibiyoterapi postoperatif 3 X1 gr devam ederek üçüncü günde sonlandırıldı. Derin Ven Trombozu profilaksisi düşük molekül ağırlıklı heparin ile (enoksaparin sodyum $0,4 \mathrm{cc} 1 \times 1$ ) yapıldı. Ameliyattan sonra ikinci gün dreni alınan hastaların, ameliyat sonrası ödem ve ağrının azalmasıyla birlikte (genellikle 7-10'uncu günler) aktif ve yardımlı ayak bileği hareketlerine başlandı. Radyolojik kontrollerde ossöz konsolidasyon görülene dek yük verilmeden koltuk değnekleriyle hastalar mobilize edildi. Ortalama ikinci ayda tam yük verdirildi. 
Poliklinik kontrolüne gelen hastaların tüm ortopedik muayeneleri yapılıp, ayak bileklerinin AP ve lateral grafileri çekildi. Hastalar American Orthopaedic Foot and Ankle Society (AOFAS) skorlamasına göre değerlendirildi [7]. Bu protokolde değerlendirme sağlam ayak bileği ile hasarlanmış ayak bileği karşılaştırılarak yapılır.

\section{Bulgular}

Çalışmamızda olgularımızın ortalama takip süresi 18,6 ay (7-34) olarak bulundu. Yirmi altı Pilon kırıklı hastanın 17'sinde (bilateral Pilon kırığı olan hastanın sağ tarafı) ikinci cerrahi girişime gerek kalmadan ortalama 4 ayda kaynama gözlendi. AOFAS skoru ortalama 76,7 olarak gözlendi.

Birden fazla cerrahi girişim yapılan olgularda AOFAS skoru ortalama 67,4 olarak gözlendi. İki Pilon kırıklı olguya (tip I, tip II açık kırık) ilk seansta uygulanan uniplan eksternal fiksatör sonrası ikinci seansta bilgisayar destekli eksternal fiksatör uygulandı (2'nci hafta ve 6'ncı hafta) ve ortalama 5 ayda kaynama gözlendi. Üç pilon kırıklı olguya (tip II, tip III B açık kırık) ortalama 7,6 ayda pseudoartroz tanısı ile (5'inci 8,5 ve 9'uncu ay) ikinci girişim (2 bilgisayar destekli eksternal fiksatör, 1 açık redüksiyon internal tesbit +3 olguya da allogreftleme) uygulandı ve ortalama 6 ayda kaynama gözlendi. Bir olguya uygulanan açık redüksiyon internal tesbit (distal anatomik plak) sonrası cilt nekrozu ve yara yeri enfeksiyonu gelişmesi nedeniyle postoperatif 3 hafta materyal çıkarımı+uniplan eksternal fiksatörle tespit operasyonu yapıldı. Enfeksiyon geriledikten sonra cilt greftleme operasyonu yapıldı. Sekizinci ayda kaynama gözlendi. Bir olguda dış merkezde yapılan açık redüksiyon internal tesbit sonrası malunion gelişmesi sonucu postoperatif 4 yılda ilk seansta materyal çıkarımı+düzeltici osteotomi uygulandı. Postoperatif 1 hafta sonra ilizarov eksternal fiksatör uygulandı ve 2,5 ay sonra kaynama gözlendi. Bir olguda (tip III A) yapılan açık redüksiyon internal tesbit+allogreftleme (medial anatomik plak) sonrası yara yerinde enfeksiyon gelişmesi nedeniyle postoperatif 3'üncü hafta materyal çıkarımı+ilizarov eksternal fiksatör tespiti yapıldı, postoperatif 17'nci ayda pseudoartroz tanısı ile osteotomi+ilizarov eksternal fiksatör+allogreftleme yapıldı ve 7'nci ayda kaynama gözlendi. Bir olguda kaynama gözlenemediği için artrodez yapıldı.

İki olguya $(\% 7,6)$ kompartman sendromu tanısı ile fasiotomi açıldı. İki olguya $(\% 7,6)$ cilt nekrozu gelişmesi nedeniyle yüzeyel cilt greftlemesi uygulandı. Üç olguda $(\% 11,5)$ yara yeri enfeksiyonu gelişmesi nedeniyle implant çıkarımı uygulandı. Beş olguya $(\% 19,2)$ allogreft (Deminarelize Bone Matrix ve cancellos chips) uyguland. Sekiz olguda $(\% 30,7)$ Sudeck artrofisi gelişti, 7 olguda $(\% 26,9)$ osteoartrit gözlendi.

Yirmi altı Pilon kırığının 15'inde (\%57,6) AOFAS skoru 70 ve üzeri çıktı. Bunların 4’ü açık kırıktı (2 tip I, 1 tip II, 1 tip IIIB). On olguda $(\% 38,4)$ AOFAS skoru 50-70 arası çıktı. Bunların 3'ü açık kırıktı (tip III). İki olguda $(\% 7,6)$ AOFAS skoru 30-50 arası çıktı. Bunların biri açık kırıktı (tip II) Şekil 1.

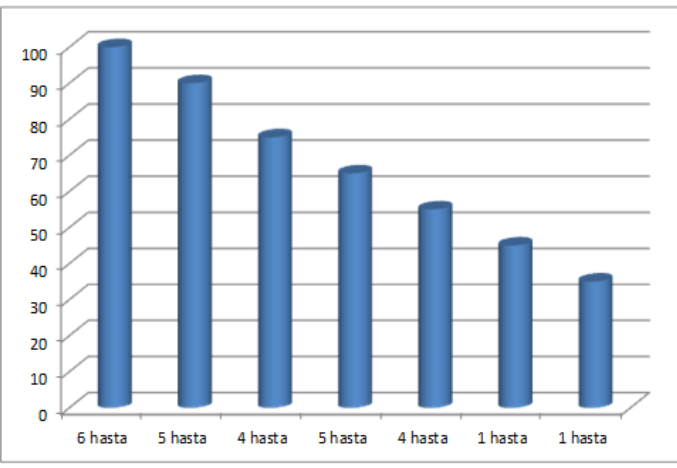

Şekil 1. AOFAS skorlamasının olgular üzerindeki dağılımı. 


\section{Tartışma}

Pilon kırıkları, distal tibia ve ayak bileği ekleminin en ciddi yaralanmalarındandır. Alt ekstremite kırıklarının yaklaşık \%1'i, tüm tibia kırıklarının ise \%7-10'u Pilon kırıklarıdır. Pilon kırıklarının \%25'i açık kırık şeklindedir [1]. Bu olguların \%85'inde fibula kırığının da eşlik ettiği bilinmektedir. Etiyolojide yüksekten düşme (yüksek enerjili aksiyel yüklenme) önemli yer işgal ettiğinden birlikte kalkaneus, tibia plato, pelvis ve vertebra kırıkları sık görülür $[8,9]$. Çalışmamızda açık kırık oranı \%30,7, eşlik eden fibula kırığı oranıda \%73,7 olarak gözlendi. Etiyolojide yüksekden düşme $\% 40$ ile ilk siray1 almaktadır. Yüksekten düşen 5 olguda (\%50) eşlik eden kırıklar mevcut idi. Tscherne ve Goetzen tip 4 yumuşak doku yaralanması olan 5 olguda kaynamayı ortalama 7 ayda gözlemledik ve AOFAS skoru ortalamasını 58 olarak bulduk. Yumuşak doku yaralanma miktarı arttıkça kaynamama ve komplikasyon oranının arttığını düşünmekteyiz.

Pilon kırıklarının tedavisinde çok farklı yöntemler kullanılabilmektedir. Kırığın tipi, cilt ve yumuşak dokuların durumu, kemiğin kalitesi, damar-sinir yapılarının durumu, eklem hasarı ve kaybı, eşlik eden bölgesel ve sistemik hastalıkların bulunup bulunmamasına göre tedavi yöntemi değişir [4].

Öncelikle cerrahi veya cerrahi dışı tedavilerden hangisinin seçileceğine karar verilmelidir. Cerrahi dışı tedavi olarak, kapalı yerleştirme ve sirküler alçı, kalkaneustan iskelet traksiyonu sonrası sirküler alçı uygulanabilir. Cerrahi tedavide son yıllarda eksternal tespit, minimal içten tespitle birlikte eksternal tespit, hibrid eksternal tespit, açık yerleştirme ve katı içten tespit, minimal invaziv perkutan plak tespiti veya bu yöntemlerin kombinasyonları kullanılmaktadır [9-11].

Çalışmamızda olgularımıza ilk girişim olarak en sık açık redüksiyon internal tesbit (10 interfragmanterik vida ve $\mathrm{K}$ teli, 4 plak-vida ile tespit) uyguland $1 \% 53,8)$. Eksternal fikasyon $(\% 26,9)$ ve hibrid eksternal fiksatörle tespit $(\% 19,2)$ daha az s1kl1kla uygulandi. redüksiyon internal tesbit ile Pilon kırıklarında eklemin tam anatomik redüksiyonunun daha etkili sağlanabileceğini düşünmekteyiz. Ayrıca ayak bileğine erken hareket verme kolaylığı sağladığından dolayı daha etkili bir tedavi modeli olduğunu düşünmekteyiz.

Ruedi ve Allgöwer [12], açık redüksiyon internal tesbit ve erken hareketle \%90'a varan iyi sonuçlar bildirmişlerdir. Ancak serilerindeki olguların büyük çoğunluğunu düşük enerjili rotasyonel travmalarla oluşan kırıklar oluşturmuştur. Oysa aynı metodla tip 3 kırıklarda başarı oranı bir çok seride \%50'i aşmamakta ve ciddi oranda derin enfeksiyon ve posttravmatik artrit gibi komplikasyonlarla karşılaşılmaktadır. Ovadia ve Beals, Bourne [13, 14], fonksiyonel sonuçların kırık tipleriyle ilişkili olduğunu belirtmişler ve kırık kompleks hale geldikçe sonuçların kötüleştiğine dikkat çekmişlerdir.

Horisberger ve ark. [15] Pilon kırıklı 141 hastada yaptıkları çalışmada, posttravmatik artroz gelişiminin geçirilen yaralanmanın şiddeti, kırığın tipi, iyileşme sürecinde gelişen komplikasyonlar ve hastanın yaşına bağlı olduğunu ortaya koymuşlardır.

Bourne ve ark. [14], tip I ve tip II kırıklarda, cerrahi tedavi ile $\% 80$ başarı yakaladıklarını ancak, tip III kırıklarda bu oranın \%44'lere düştüğünü bildirdiler. Kelam ve Waddell [16], çoğu rotasyonel kuvvetlere bağlı gelişmiş olan Pilon kırıklarında \%94 iyi ve mükemmel sonuç bildirirken, yüksek enerjili travmalara bağlı kırıklarda bu oranın \%53'lere düştüğünü ifade etmişlerdir. $\mathrm{Bu}$ araştırmacılar rijit internal fiksasyonu takiben erken dönemde başlanan eklem hareketlerinin tedavinin başarısını arttırmada en önemli etken olduğunu bildirdiler. Serilerindeki tip III kırıklarda \%25 kaynamama, \%13 infeksiyon görüldü, \%32 hastada sekonder artrodez yaptıklarını bildirmiş̧lerdir.

Çalışmamızda açık redüksiyon internal tesbit (interfragmanterik vida-K teli ve plak-vida ile tespit)sonrası \%76 oranında kaynama gözledik. Üç olguda (\%24) derin infeksiyon nedeni ile implant çıkarımı yapıldı. Beş adet $(\% 19,2)$ tip III kırıkta \%20 kaynamama gözlendi. AOFAS skoru ortalama 61,6 olarak gözlendi. Tip III tüm olgularda osteoartrit gözlendi. Eklem yüzeyinde parçalanma miktarı arttıkça literatürle uyumlu şekilde daha kötü sonuçlar elde edileceğini düşünüyoruz. 
Bone ve ark. [17], 18 hastaya sınırlı internal fiksasyon ile kombine eksternal fiksasyon uyguladılar.On bir hastada iyi ve mükemmel sonuç elde ettiler. İnfeksiyon ve yara sorunu ile karşılaşmadılar. Küçükkaya ve ark. [18], 21 pilon kırıklı hastaya sınırlı açık yerleştirme eksternal tespit veya kapalı eksternal tespit uygulamışlardır. Hastalarının 14'ü Ruedi-Allgöwer sınıflamasına göre tip 3 kırık olan olguların 5 'inde mükemmel, 5'inde iyi, 7'sinde orta ve 5'inde kötü sonuç elde etmişlerdir. Karas ve Weiner [19], sinırlı internal fiksasyon ve hibrid eksternal fiksasyon ile tedavi ettikleri 26 olguda, \%70,5 iyi ve mükemmel sonuç bildirdiler. Bunların 13'ü (\%50) tip II kırıktı ve 9'unda başarılı sonuç alındığı bildirildi. Diafizde parçalanmanın fazla olduğu deplase Pilon kırıklarında, internal ve eksternal fiksasyonun birlikte kullanılmasının klinik sonuçları iyileştirdiğini ve komplikasyon riskini azalttığını, bu nedenle kombine tedavinin tercih edilmesi gerektiğini yayınladılar.

Çalışmamızda 7 olguda $(\% 26,9)$ ilk girişimde eksternal fiksatör uyguladık 4 olguda $(\% 57,1)$ ikinci bir cerrahi girişime gerek kalmadan kaynama izlendi. AOFAS skoru ortalama 83 olarak izlendi. İki olguda $(\% 28,5)$ nonunion ve deformite nedeniyle ikinci girişim olarak bilgisayar destekli eksternal fiksatör uygulaması yapıldı. Bunlardan biri açık kırıktı. Bir taneside bilateral Pilon kırıklı hastanın sol tarafi idi (kaynamama nedeni ile 5 ay sonra opere edildi). Bir olguyada pseudoartroz tanısı ile açık redüksiyon internal tesbit (distal anatomik plak+allogreftleme) yapıldı. AOFAS skoru ortalama 63 olarak bulundu. Beş olguya ilk olarak $(\% 19,2)$ sınırlı internal fiksasyon ile kombine eksternal fiksasyon uyguladık 3 olguda (\%60) kaynama gözlendi AOFAS skoru ortalama 61,6 olarak gözlendi. İki olguya (\%40) postoperatif 1,5 ay ve 8,5 ayda bilgisayar destekli eksternal fiksatör yapıldı $(8,5$ ay sonra opere edilen olguda pseudoartroz tanıs1 konduğundan otogreftleme ve allogreftleme yapıld1). AOFAS skoru ortalama 78,5 olarak bulundu.

Çalışmamızda takip ettiğimiz 26 olgunun 15 'inde $(\% 57,6)$ AOFAS skoru 70 ve üzeri çıktı. Bunların 4'ü açık kırıktı (2 tip I, 1 tip II, 1 tip IIIB). On olguda $(\% 38,4)$ AOFAS skoru 50-70 arası çıktı. Bunların 3'ü açık kırıktı (tip III). İki olguda $(\% 7,6)$ AOFAS skoru 30-50 arası çıktı. Bunların 1'i açık kırıktı (tip II).Uygun cerrahi teknikler ve erken rehabilitasyon ile AOFAS skorunun yükselebileceğini ve fonksiyonel ayak bileği sağlanabileceğini düşünmekteyiz (Resim 3).

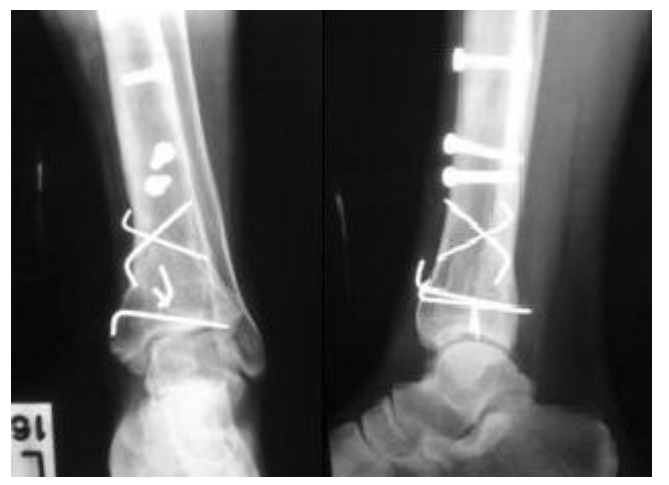

Resim 3. Beş ay izlem sonu AP ve lateral grafileri (AOFAS skoru: 87).

Artrodez çok tercih edilmeyen bir seçenek olmasına rağmen, eklemin restore edilemeyecek derecede fazla parçalandığı olgularda primer artrodez, posttravmatik artrite bağlı ağrılı ayak bileklerinde ağrıyı ortadan kaldırmak için sekonder artrodez uygulanabilir.

Ganz [20], çok ümitsiz görünen ve cerrahi tedavi düşünülmeyen çok parçalı kırıklara konservatif tedavi şansının verilmesini, çünkü bazen bunlardan tatminkar sonuçların alınabildiğini bildirmiştir.Ağrılı bir ayak bileği ortaya çıkarsa sekonder artrodezin yapılabileceğini rapor etmiştir. Çalışmamızda hiçbir olguda primer artrodez planlamadık ve uygulamadık. Biz primer cerrahide eklem yüzünün tam restore edilmesinden yana olan 
literatür görüşüne göre tüm olgularda eklem yüzünü restore ettik. Çalışmamızda bir olguda artrodez gerektiren ağrılı ayak bileği ile karşılaştık. Posttravmatik artrit oranımız $\% 26,9$, Sudeck atrofisi oranımızda \%30,7 olarak gözlendi. Erken hareket ve rehabilitasyon programı ile komplikasyonların daha da azalacağını düşünmekteyiz.

Pilon kırıkları, çok sık görülmeyen, ancak başarılı sonuç almayı engelleyen birçok faktöre sahip ayak bileğinin ciddi yaralanmalarıdır. Eklem yüzündeki parçalanma ve kıkırdağın metafize doğru çökmesi, metafizdeki parçalanma ve kemik kaybı, yumuşak doku yaralanmasının derecesi ve açık kırık olması tedaviyi güçleştirerek prognozu olumsuz etkileyen faktörlerdir.

Başarılı sonuç alabilmek için çok iyi preoperatif planlama yapılmalıdır. Biyolojik prensiplere uygun, atravmatik yumuşak doku diseksiyonu, eklem yüzünün anatomik restorasyonu, gerekirse kemik grefti kullanarak yapılan rijit fiksasyon ve erken dönemde ayak bileği hareketlerine başlanması ile başarılı sonuçlar alınabilir. Ancak, Pilon kırıklarının tümü için geçerli tek bir başarılı tedavi yöntemi yoktur. Her kırığın ayrı olarak değerlendirilmesi, tedavinin iyi planlanarak cerrahi ilkelere uyulması gereklidir.

\section{Kaynaklar}

1. Bourne RB. Pylon fractures of the distal tibia. Clin Orthop Rel Res 1989; 240: 42-6.

2. Mast JW, Spiegel PG, Pappas JN. Fractures of the tibial pilon. Clin Orthop Relat Res 1988; 230: 68-82.

3. Brumback RJ, McGarvey WC. Fractures of the tibial plafond. Evolving treatment concepts for the pilon fracture. Orthop Clin North Am 1995; 26: 273-85.

4. Wang C, Li Y, Huang L, Wang M. Comparison of two-staged ORIF and limited internal fixation with external fixator for closed tibial plafond fractures. Arch Orthop Trauma Surg 2010; 130: 1289-97.

5. Gustilo RB, Anderson JT. Prevention of infection in the treatment of one thousand and twenty-five open fractures of long bones: Retrospective and prospective analyses. J Bone Joint Surg Am 1976; 58: 453-8.

6. Murphy WM, Leu D. Fracture classification: Biological significance. In: Rüedi TP, Murphy WM, editors. AO principles of fracture management. Stuttgart: Thieme 2000; 45-58.

7. Kitaoka HB, Alexander IJ, Adelaar RS, Nunley JA, Myerson MS, Sanders M. Clinical rating systems for the ankle-hindfoot, midfoot, hallux, and lesser toes. Foot Ankle Int 1994; 15: 349-53.

8. Chapman MW, Bray TJ. Operative Ortophaedics Vol, Pilon fractures of the tibia. 1993; 711-29.

9. Helfet DL, Koval K, Pappas J, Sanders RW, DiPasquale T. Intraarticular "pilon" fracture of the tibia. Clin Orthop Relat Res 1994; 298: 221-8.

10. Öztürkmen Y, Akar B, Balioğlu MB, Karlı M. Pilon Kırıklarında Sınırlı Açık Redüksiyon ve Eksternal Fiksasyon. Acta Orthop Trumatol Turc 2001; 35: 23644.

11. Geisser WB, Tsao AK, Hughes JL. Fractures and injuries of the ankle.Fractures in Adults Rockwood and Green's 4th ed. Vol. 2, Lippincott-Raven. 1996: 220142.

12. Rüedi T. Fractures of the lower end of the tibia into the ankle joint: results 9 years after open reduction and internal fixation. İnjury 1973; 5: 130-4.

13. Ovadia DN, Beals RK. Fractures of the tibial plafond. J Bone Joint Surg Am 1986; 68: 543-51.

14. Bourne RB, Rorabeck $\mathrm{CH}$, Macnab J. Intra-articular fractures of the distal tibia: the pilon fracture. J Trauma 1983; 23: 591-6.

15. Horisberger $\mathrm{M}$, Valderrabano V, Hintermann B. Posttraumatic ankle osteoarthritis after ankle-related fractures. J Orthop Trauma 2009; 23: 60-7. 
16. Kellam JF, Waddell JP. Fractures of the distal tibial metaphysis with intraarticular extension--the distal tibial explosion fracture. J Trauma 1979; 19: 593601.

17. Bone L, Stegemann P, McNamara K, Seibel R. External fixation of severely comminuted and open tibial pilon fractures. Clin Orthop 1993; 292: 101-07.

18. Küçükkaya M, Kabukçuoğlu Y, Tezer M, Armağan R, Kuzgun Ü. Tibia pilon kırıklarının eksternal fiksatörle tedavisi: Kapalı veya sınırlı açık redüksiyon tekniği. Acta Orthop Trauma Turc 2001; 35: 425-30.

19. Karas EH, Weiner LS. Displaced pilon fractures. An update. Orthop Clin North Am 1994; 25: 651-63.

20. Etter C, Ganz R. Long-term results of tibial plafond fractures treated with open reduction and internal fixation. Arch Orthop Trauma Surg 1991; 110: 277-83. 